\title{
Regulation of the Tricarboxylic Acid Cycle and Poly- $\beta$-hydroxybutyrate Metabolism in Azotobacter beijerinckii Grown under Nitrogen or Oxygen Limitation
}

\author{
By FRANK A. JACKSON* AND EDWIN A. DAWES \\ Department of Biochemistry, University of Hull, Hull HU6 ${ }_{7} R X$
}

(Received 22 July 1976)

\begin{abstract}
SUMMARY
Azotobacter beijerinckii was grown in ammonia-free glucose/mineral salts media in chemostat culture under oxygen or nitrogen limitation. Selected enzymes of the tricarboxylic acid cycle and poly- $\beta$-hydroxybutyrate metabolism were monitored in relation to oxygen supply for both steady and transition states. Two dissolved oxygen concentrations were used for the nitrogen-limited steady state to investigate the possible effects of respiratory protection of nitrogenase on these enzymes. The levels of NADH oxidase, isocitrate dehydrogenase and 2-oxoglutarate dehydrogenase increased markedly on relaxation of oxygen limitation while pyruvate dehydrogenase and citrate synthase were relatively unaffected. $\beta$-Ketothiolase and acetoacetyl-CoA reductase levels decreased as oxygen limitation was relaxed. Respiratory activity, as measured by the $Q_{\mathrm{o}_{2}}$ value, increased with oxygen supply rate. Imposition of oxygen limitation on a nitrogen-limited culture caused an immediate increase in the NADH/NAD ratio but this rapidly readjusted to its previous steady-state value. These changes are discussed in relation to respiratory protection of nitrogenase and poly- $\beta$-hydroxybutyrate metabolism in $A$. beijerinckii.
\end{abstract}

\section{INTRODUCTION}

Poly- $\beta$-hydroxybutyrate (PHB), a reserve polymer peculiar to micro-organisms, occurs widely in both Gram-positive and Gram-negative bacteria. It is particularly characteristic of the nitrogen-fixing Azotobacter and Azotobacter beijerinckii may accumulate up to $70 \%$ of its dry weight as polymer (Stockdale, Ribbons \& Dawes, I968). Chemostat experiments revealed that oxygen limitation, rather than nitrogen limitation, initiated synthesis of PHB and that the PHB content of oxygen-limited cultures was inversely proportional to the growth rate (Senior et al., 1972).

A cyclic mechanism for the biosynthesis and degradation of PHB was proposed by Senior \& Dawes (1973), together with a regulatory scheme suggesting control of PHB metabolism by the redox state of the cell and the availability of $\mathrm{CoASH}$, pyruvate and 2-oxoglutarate. $\beta$-Ketothiolase plays a key role in this regulatory process. A similar scheme was suggested for Alcaligenes eutrophus HI6 (Hydrogenomonas eutropha HI6) (Oeding \& Schlegel, 1973). In $A$. beijerinckii, acetyl-CoA can be oxidized via the tricarboxylic acid cycle or can serve as a substrate for PHB biosynthesis, and the diversion depends on environmental conditions. The potential rate of oxygen consumption for oxygen-limited cultures was lower than for carbon-limited cultures, indicating a possible repression and/or inhibition of certain enzymes associated with oxidation. Senior \& Dawes (I97I) also found that glucose catabolism, which occurs via the Entner-Doudoroff pathway, was inhibited by the action of NADPH and

* Present address: Cyanamid of Great Britain Ltd, Fareham Road, Gosport, Hants, POr3 oAS. 
NADH on glucose-6-phosphate dehydrogenase. Citrate synthase was strongly inhibited by $\mathrm{NADH}$, and isocitrate dehydrogenase, thought to provide the major portion of reducing equivalents for nitrogen fixation (Barrera \& Jurtshuk, 1970), was inhibited by ATP, NADH and NADPH. These inhibitory agents would be expected to accumulate during oxygenlimited growth. This evidence for the fine control of enzymes of glucose oxidation and the tricarboxylic acid cycle has now been supplemented by a study of the levels of NADH oxidase, citrate synthase, isocitrate dehydrogenase, 2-oxoglutarate dehydrogenase, $\beta$-ketothiolase and acetoacetyl-CoA reductase in the nitrogen-fixing organism when subjected to nitrogen or oxygen limitation. To investigate the possible effects of respiratory protection of nitrogenase, oxygen was supplied to nitrogen-limited cultures at two different rates and enzyme levels during transitional and steady states were determined.

Senior \& Dawes (1971) suggested that PHB served not only as a reserve of carbon and energy but also as a sink of reducing power, and that the oxidation-reduction state of the cell is an important regulatory factor. To test this hypothesis intracellular NADH/NAD ratios were also measured.

\section{METHODS}

Organism. The organism was a capsuleless mutant of Azotobacter beijerinckii first isolated by Senior et al. (1972). It was indistinguishable from the wild-type strain in the standard bacteriological tests (Jensen, 1954).

Growth of the organism in a chemostat. Details of the chemostat, maintenance of the organism, growth of inocula for chemostat cultures, growth media, growth conditions, bacterial dry weight measurement, and determination and control of dissolved oxygen tension in the culture have been described previously (Senior et al., 1972). The dilution rate in all experiments was $0^{\cdot} \mathrm{I} \mathrm{h}^{-1}$. The oxygen electrode (L. H. Engineering Co., Bells Hill, Stoke Poges, Bucks.) was sterilized in situ by autoclaving with the culture vessel. Redox potential was not measured; for oxygen-limiting conditions (undetectable dissolved oxygen tension), oxygen was supplied at a flow rate of $30 \mathrm{ml} \mathrm{min}^{-1}$ and nitrogen at $800 \mathrm{ml} \mathrm{min}^{-1}$. Two nitrogen-limiting (flow rate $20 \mathrm{ml} \mathrm{min}^{-1}$ ) steady states were used: one with the oxygen flow rate at $60 \mathrm{ml} \mathrm{min}^{-1}$ and argon at $591 \mathrm{ml} \mathrm{min}^{-1}$, and the other with the oxygen flow rate at $82 \mathrm{ml} \mathrm{min} \mathrm{m}^{-1}$ and argon at $59 \mathrm{I} \mathrm{ml} \mathrm{min} \mathrm{m}^{-1}$. The dissolved oxygen tension controller was not used for these transitions as it might have masked the absolute effect of increasing the oxygen concentration of the culture. All the transitions were carried out during one prolonged chemostat run, except separate experiments were done for NADH and NAD measurements.

Analyses. The determination of protein, and the preparation and determination of acetylCoA and acetoacetyl-CoA have been described previously (Senior \& Dawes, 1973). Glucose estimations were as described by Senior et al. (1972). The PHB content was assayed by a modification of the method of Law \& Slepecky (1961). The bacterial PHB was rendered accessible to chloroform extraction by freeze-drying the organisms immediately after sample collection. PHB was recovered after extraction of non-PHB lipids by filtration instead of centrifugation.

Enzyme assays. Bacterial extracts were prepared by the methods of Senior \& Dawes (1973). All enzyme assays were performed at $30^{\circ} \mathrm{C}$ with a Pye Unicam SPr 800 recording spectrophotometer under previously determined optimum conditions.

NADH oxidase (EC. I .6.99.3). This was assayed by measuring the decrease in extinction at $340 \mathrm{~nm}$ (due to NADH oxidation) in a cuvette ( $1 \mathrm{~cm}$ path-length) containing, in a total volume of I ml: I $\cdot 0 \mathrm{M}-\mathrm{KH}_{2} \mathrm{PO}_{4} / \mathrm{K}_{2} \mathrm{HPO}_{4}$ buffer, $\mathrm{pH} 7 \cdot 2$, containing I mM-mercaptoethanol, $200 \mu \mathrm{l} ; 25$ mM-NADH, $15 \mu \mathrm{l}$; bacterial extract, 10 to $100 \mu \mathrm{l}$. 
2-Oxoglutarate dehydrogenase (EC. I.2.4.2) and pyruvate dehydrogenase (EC. I.2.4. I). Due to the presence of NADH oxidase in crude extracts, acetyl-NAD replaced NAD as coenzyme in these assays (Amarasingham \& Davis, 1965). A cuvette contained, in a total volume of $\mathrm{I} \mathrm{ml:} \mathrm{I} \cdot 0 \mathrm{M}$-Tris/ $\mathrm{HCl}$ buffer, $\mathrm{pH} \mathrm{7.9}$, containing I mM-dithiothreitol, $200 \mu \mathrm{l}$; I $66 \mathrm{mM}$-L-cysteine, $33 \mu \mathrm{l}$; 6.2 mM-CoASH, $20 \mu \mathrm{l}$; I5 mM-acetyl-NAD, I00 $\mu \mathrm{l}$; Io mMthiamin pyrophosphate, $50 \mu \mathrm{l} ; 0.25 \mathrm{M}-\mathrm{MgCl}_{2}$, Io $\mu \mathrm{l}$ (for 2-oxoglutarate dehydrogenase assay) or $40 \mu 1$ (for pyruvate dehydrogenase assay; see below); 0.25 M-monosodium 2-oxoglutarate or sodium pyruvate, $40 \mu 1$; extract, $100 \mu 1$. The reactants, without the substrate, were incubated for $2 \mathrm{~min}$ at $30^{\circ} \mathrm{C}$ before the reaction was initiated with substrate and the increase in extinction at $365 \mathrm{~nm}$ was measured. The millimolar extinction coefficient of acetyl-NADH was taken as $9.01 \mathrm{mmol}^{-1} \mathrm{~cm}^{-1}$ (unpublished observation). The concentration of $\mathrm{Mg}^{2+}$ used in this assay depended on the substrate being oxidized. 2-Oxoglutarate dehydrogenase was inhibited by $\mathrm{Mg}^{2+}$ concentrations in excess of $2.5 \mathrm{mM}$, whereas pyruvate dehydrogenase required at least $7.5 \mathrm{mM}-\mathrm{Mg}^{2+}$ for maximum activity.

Isocitrate dehydrogenase (EC. 1.I.1.42). A cuvette contained, in a total volume of I ml: 0.I M-Tris/HCl, $\mathrm{pH} 7.5,905 \mu \mathrm{l} ; 25 \mathrm{~mm}-\mathrm{NADP}, \mathrm{I} 5 \mu \mathrm{l} ; 40 \mathrm{mM}-\mathrm{MnCl}_{2}, 50 \mu \mathrm{l} ; 50$ mM-trisodium isocitrate, ro $\mu \mathrm{l}$; suitably diluted extract, 10 $\mu \mathrm{l}$. After $2 \mathrm{~min}$ incubation at $30^{\circ} \mathrm{C}$ the reaction was initiated by adding isocitrate and the increase in extinction at $340 \mathrm{~nm}$ measured.

Citrate synthase (EC. 4.1.3.7). This was determined in crude extracts by measuring the oxaloacetate-dependent cleavage of acetyl-CoA to CoASH. Formation of CoASH was measured at $412 \mathrm{~nm}$ by the appearance of thiol groups using Ellman's (1959) reagent. A cuvette contained, in a total volume of $\mathrm{I} \mathrm{ml:} \mathrm{I} \mathrm{M}-\mathrm{Tris} / \mathrm{HCl}$ buffer, $\mathrm{pH} 7.8$, containing $0.39 \mathrm{mg} 5,5^{\prime}$-dithiobis-(2-nitrobenzoic acid) $\mathrm{ml}^{-1}$, $100 \mu 1 ; 6$ to $8 \mathrm{~mm}$-acetyl-CoA (varied from preparation to preparation), $20 \mu \mathrm{l}$; IO mM-disodium oxaloacetate, $40 \mu \mathrm{l}$; extract, $20 \mu \mathrm{l}$. The extinction at $412 \mathrm{~nm}$ was followed to give a measure of deacylase activity and then oxaloacetate was added to start the citrate synthase reaction. A value of $13.61 \mathrm{mmol}^{-1} \mathrm{~cm}^{-1}$ was used as the millimolar extinction coefficient of thionitrobenzoate anion.

$\beta$-Ketothiolase (EC. 2.3.I.9). This was assayed in the direction of thiolysis by measuring the decrease in extinction at $305 \mathrm{~nm}$ of a magnesium-enol complex of acetoacetyl-CoA in the presence of CoASH. The apparent extinction coefficient of acetoacetyl-CoA was $17 \cdot 21$ $\mathrm{mmol}^{-1} \mathrm{~cm}^{-1}$. A cuvette contained, in a total volume of $\mathrm{r} \mathrm{ml}: \mathrm{I} \cdot \mathrm{O} \mathrm{M}$-Tris/HCl buffer, $\mathrm{pH} 7 \cdot 6$ containing I.O mM-dithiothreitol, $200 \mu \mathrm{l} ; 250 \mathrm{mM}-\mathrm{MgCl}_{2}, 96 \mu \mathrm{l} ; 6$ to $8 \mathrm{~mm}$-acetoacetyl$\mathrm{CoA}$ (varied from preparation to preparation), Io $\mu \mathrm{l}$; suitably diluted extract, Io $\mu \mathrm{l}$. The reactants, without $\mathrm{CoASH}$, were incubated at $30^{\circ} \mathrm{C}$ for $2 \mathrm{~min}$ before $\mathrm{CoASH}$ was added to start the reaction.

Acetoacetyl-CoAreductase (EC. I . I I .36). For the reductive reaction, a cuvette contained, in a total volume of $\mathrm{I} \mathrm{ml:} 100 \mathrm{mM}-\mathrm{K}_{2} \mathrm{HPO}_{4} / \mathrm{KH}_{2} \mathrm{PO}_{4}$ buffer, $\mathrm{pH} 5.5$, containing I mMdithiothreitol, $500 \mu \mathrm{l} ; 0.25 \mathrm{M}-\mathrm{MgCl}_{2}, 40 \mu \mathrm{l} ; 25 \mathrm{mM}-\mathrm{NADPH}, \mathrm{I} 5 \mu \mathrm{l} ; 6$ to $8 \mathrm{mM}$-acetoacetylCoA (varied from preparation to preparation), $20 \mu \mathrm{l}$; extract, 10 $\mu \mathrm{l}$. Slight acid destruction of NADPH occurred at $\mathrm{pH} 5.5$ and corrections had to be made. The acid destruction of NADPH was recorded for 2 min before adding bacterial extract. After a further 2 min, during which the endogenous NADPH oxidase was recorded, the reaction was started by adding acetoacetyl-CoA.

Determination of $N A D H / N A D$ ratios. A separate transition from nitrogen limitation (dissolved oxygen tension, $\mathrm{I} \cdot 8 \mathrm{kPa}=\mathrm{I} 2 \mathrm{mmHg}$ ) to oxygen limitation (dissolved oxygen tension undetectable) was done to determine NADH/NAD ratios.

Nicotinamide nucleotide extraction. The estimation of NADH/NAD ratios presents problems owing to the difficulty of preparing material for analysis without losses and without 
uncertainty as to whether oxidation or reduction has occurred during sampling and extraction (Burch, Bradley \& Lowry, 1967). The usual procedure involves two extracts, one in acid for NAD estimation and the other in alkali for NADH estimation. However, NADH may be converted to NAD on extraction with alkali and, on subsequent heating, this NAD is destroyed leading to a low NADH value. Also, on acid extraction, NAD values may be elevated due to the conversion of NADH to NAD before the sample is completely quenched. This problem is especially acute in Azotobacter because of the highly active NADH oxidase. Thus, nicotinamide nucleotides assayed in culture samples collected into a Universal bottle through the sampling port of the chemostat were totally converted to the oxidized forms; internal NADH standards were also oxidized using this sampling method. To ensure rapid transfer of samples from the chemostat, a three-way valve with a needle penetrating the culture vessel was used. Samples $(2 \mathrm{ml})$ were collected by opening the valve and ejecting portions of culture under positive pressure directly into $1 \mathrm{ml} 7 \%(\mathrm{w} / \mathrm{v})$ perchloric acid (for NAD estimations) or I $\mathrm{ml} \mathrm{I} \mathrm{M}-\mathrm{NaOH}$ (for NADH). These mixtures were then heated at $60{ }^{\circ} \mathrm{C}$ for $10 \mathrm{~min}$, and neutralized carefully with $0.8 \mathrm{ml} \mathrm{r} \cdot 2 \mathrm{M}-\mathrm{NaOH}$ or $0.8 \mathrm{ml} \mathrm{I} \mathrm{M-HCl}$ (for NAD and NADH respectively) before assay. For total NAD(H) estimations, samples were collected in $\mathrm{I} \mathrm{ml} \mathrm{O} \cdot \mathrm{I} \mathrm{M}-\mathrm{HCl}$ and kept on ice until assayed. With internal standards of NADH and NAD, interconversion or degradation of nucleotides during extraction was not more than $10 \%$ of the nucleotide present. The extracts were routinely assayed within $2 \mathrm{~h}$ of preparation and no change in levels occurred up to $8 \mathrm{~h}$ after sampling and quenching.

Nicotinamide nucleotide assay. NADH and NAD were assayed by the cycling method of Bernovsky \& Swan (1973). Standard solutions of NADH and NAD (4 $\mu \mathrm{M})$ were used to calculate the intracellular levels of NADH and NAD. No allowance was made for any intracellular compartmentation of nicotinamide nucleotides. A I cm light-path cuvette contained: $60 \mathrm{mM}$-bicine buffer $\mathrm{pH} 7.8$ containing I mM-ethylenediaminetetra-acetic acid, $2 . \mathrm{I} \mathrm{ml} ; 5 \mathrm{M}$ ethanol in 60 mM-bicine $\mathrm{pH} 7.8,0.3 \mathrm{ml} ; 25 \mathrm{~mm}$-phenazine ethosulphate, $0.2 \mathrm{ml} ; 6.0 \mathrm{~mm}$ thiazoyl blue, $0.2 \mathrm{ml}$; standard or sample, $0.2 \mathrm{ml}$. The mixture was pre-incubated in the dark for $5 \mathrm{~min}$ at $30^{\circ} \mathrm{C}$, and the reaction was started by adding alcohol dehydrogenase (no. A-I 762, Sigma; $60 \mathrm{mg} \mathrm{ml}^{-1}$, suspension in ammonium sulphate), Io $\mu 1$.

Determination of oxo acids. Dinitrophenylhydrazone derivatives of culture supernatants and standards were prepared by the method of Friedemann \& Haugen (1943) adapted by Sherma \& Zweig (1971). Prepared hydrazone derivatives were co-chromatographed with those of pyruvate, 2-oxoglutarate and oxaloacetate standards according to the method of Byrne (1965).

\section{RESULTS}

\section{Transition from oxygen limitation to nitrogen limitation}

Oxygen-limited chemostat cultures of $A$. beijerinckii accumulate large quantities of PHB and previously we observed that on transition to a carbon limitation the PHB content decreased rapidly to a very low value (Senior et al., 1972). The present experiments were designed to study the response of various enzymes to the transition from an oxygen to a nitrogen limitation with two different concentrations of dissolved oxygen $(0.8 \mathrm{kPa}=6 \mathrm{mmHg}$, and $\mathrm{I} .6 \mathrm{kPa}=\mathrm{I} 2 \mathrm{mmHg}$ ), and so compare conditions where respiratory protection of the nitrogenase system would be invoked with those where it would not be expected to be fully operational.

The dry weight of the culture fell markedly on relaxation of the oxygen limitation (Fig. I $a$ ), essentially reflecting the loss of PHB from the organisms, but the dry weight of the nitrogenlimited steady-state culture was slightly higher than the minimum transition value. Increasing 


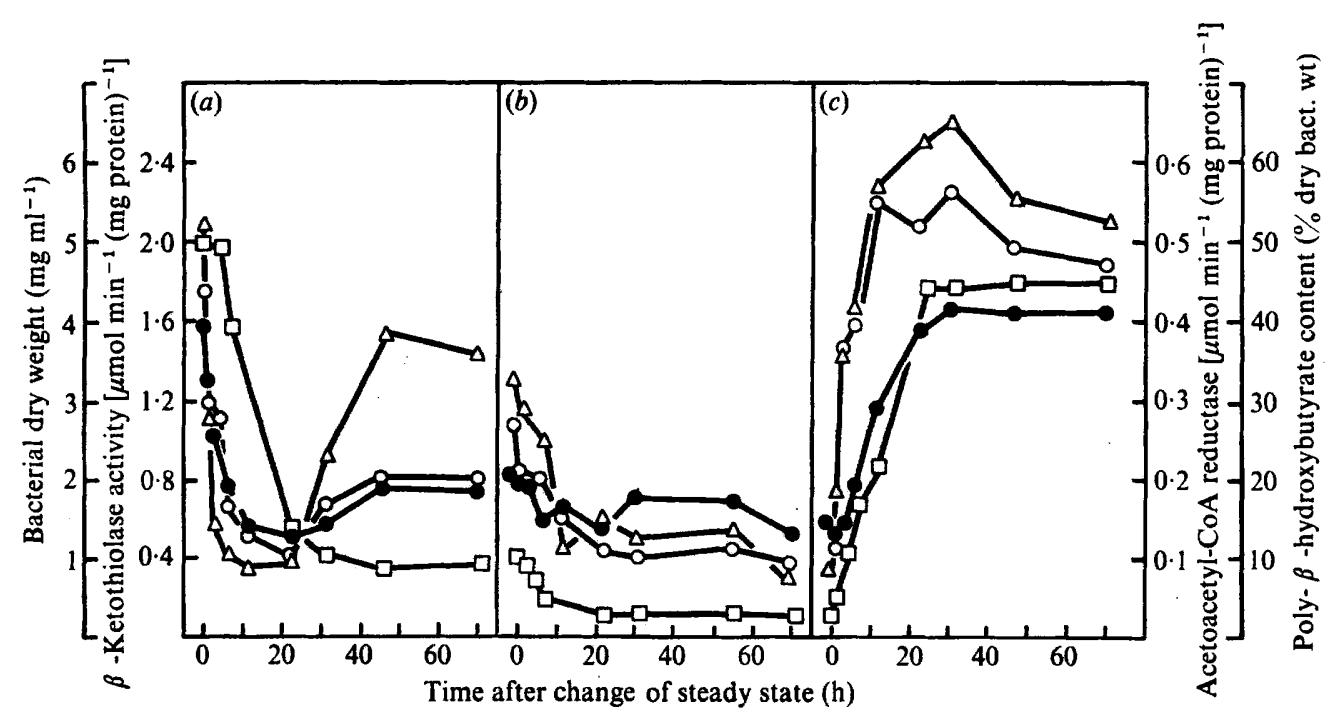

Fig. I. Effect of transition from oxygen to nitrogen limitation, and vice versa, of a chemostat culture of $A$. beijerinckii on $\beta$-ketothiolase $(\triangle)$ and acetoacetyl-CoA reductase $(O)$ levels, poly- $\beta$ hydroxybutyrate content $(\square)$ and bacterial dry weight $(O)$. The dilution rate was $0 \cdot \mathrm{I} \mathrm{h}^{\mathbf{- 1}}$. At zero time, the cultural conditions were changed from $(a)$ oxygen limitation [undetectable dissolved oxygen tension (d.o.t.)] to nitrogen limitation (d.o.t. $0.8 \mathrm{kPa}) ;($ b) nitrogen limitation (d.o.t. $0.8 \mathrm{kPa})$ to nitrogen limitation (d.o.t. $\mathrm{I} \cdot 6 \mathrm{kPa}$ ); $($ c) nitrogen limitation (d.o.t. $\mathrm{I} \cdot 6 \mathrm{kPa}$ ) to oxygen limitation.

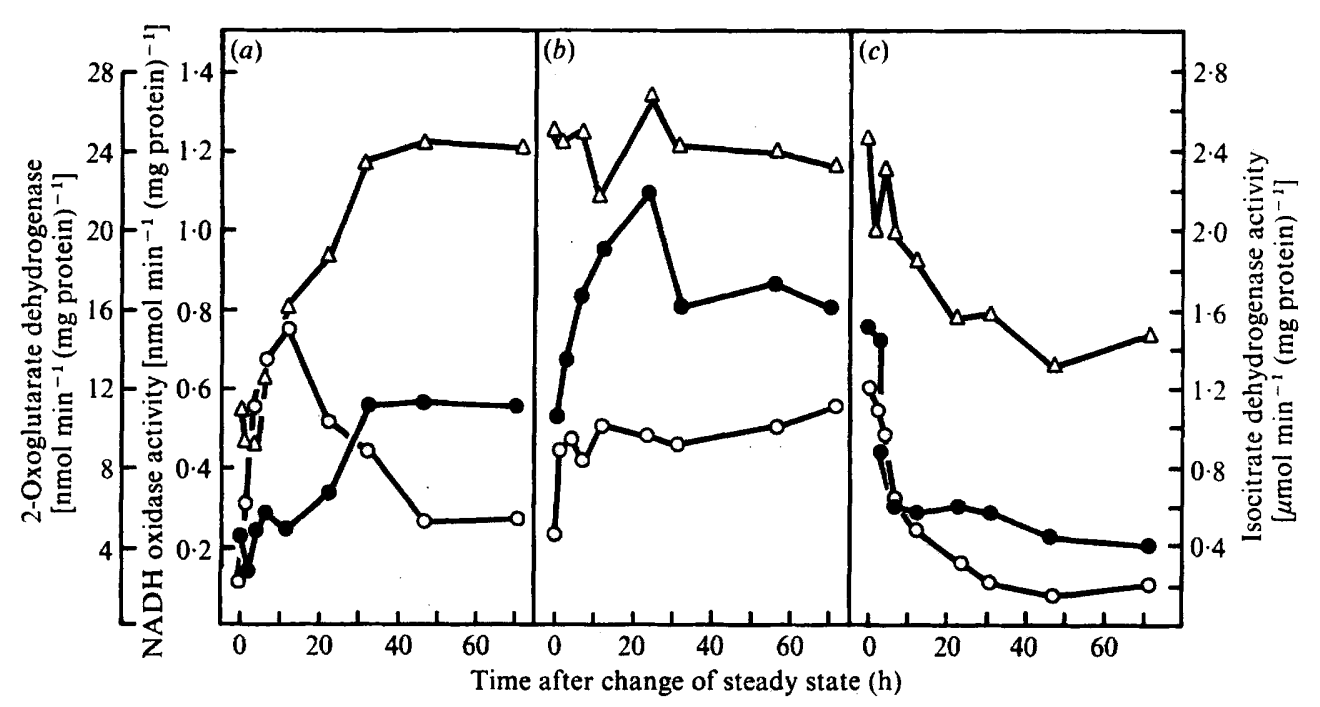

Fig. 2. Effect of transition from oxygen to nitrogen limitation, and vice versa, of a chemostat culture of $A$. beijerinckii on NADH oxidase ( $O$ ), 2-oxoglutarate dehydrogenase $(O)$ and isocitrate dehydrogenase $(\triangle)$ levels. Details as for Fig. I. 


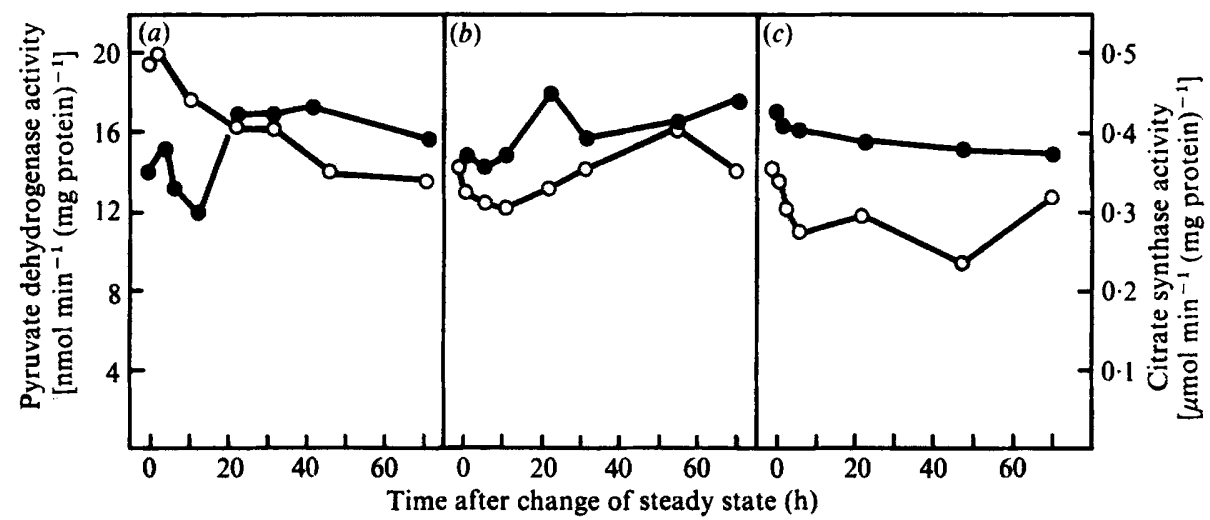

Fig. 3. Effect of transition from oxygen to nitrogen limitation, and vice versa, of a chemostat culture of $A$. beijerinckii on citrate synthase $(O)$ and pyruvate dehydrogenase $(O)$ levels. Details as for Fig. 1.

the dissolved oxygen concentration from 0.8 to $\mathrm{I} \cdot 6 \mathrm{kPa}$ caused a slight decrease in the dry weight and PHB content of the culture (Fig. I $b$ ). Imposition of an oxygen limitation on the nitrogen-limited culture (Fig. Ic) produced a dramatic increase in its dry weight and PHB content. The changes in dry weight and intracellular PHB were mirrored by changes in the levels of the two enzymes of PHB biosynthesis assayed, $\beta$-ketothiolase and acetoacetylCoA reductase (Fig. I).

The changes in NADH oxidase, isocitrate dehydrogenase and 2-oxoglutarate dehydrogenase for the same transitions are recorded in Fig. 2. The level of NADH oxidase rose rapidly for the first $\mathrm{I} 2 \mathrm{~h}$ after relaxation of the oxygen limitation but then declined to a steady-state value of about 2.5 times that of the oxygen-limited organisms. Increasing the dissolved oxygen concentration from 0.8 to $\mathrm{I} \cdot 6 \mathrm{kPa}$ caused a further increase in the steadystate NADH oxidase level. Azotobacter species are noted for their extremely high levels of NADH oxidase, which is associated with the process of respiratory protection of the nitrogenase system, and the level of this enzyme reflects the environmental oxygen concentration. Thus, the imposition of an oxygen limitation (Fig. $2 c$ ) resulted in an immediate, marked decrease in the level of $\mathrm{NADH}$ oxidase. Isocitrate dehydrogenase and 2-oxoglutarate dehydrogenase both increased markedly on relaxation of the oxygen limitation (Fig. $2 a$ ) and the latter enzyme showed a further significant increase when the dissolved oxygen concentration was increased from 0.8 to $1.6 \mathrm{kPa}$ (Fig. $2 b$ ). The levels of both enzymes were restored to their original values when an oxygen limitation was re-imposed (Fig. $2 c$ ). In contrast, the levels of citrate synthase and pyruvate dehydrogenase were relatively unaffected by the transitions (Fig. 3).

$Q_{\mathrm{o}_{2}}$ values, glucose yield coefficients ( $Y_{\mathrm{G}} ; \mathrm{g}$ organism formed per mol glucose utilized) and supernatant glucose concentrations were also measured (Fig. 4). The $Q_{\mathrm{o}_{2}}$ values $\left[\mu \mathrm{l} \mathrm{h}{ }^{-1}\right.$ (mg dry wt $)^{-1}$ in situ increased with increasing oxygen concentration from 70 under oxygen limitation to 330 and 640 respectively for the nitrogen-limited cultures with dissolved oxygen concentrations of 0.8 and I. $6 \mathrm{kPa}$. These values compared favourably with those of 75.5 for oxygen-limited and 622 for $2.0 \mathrm{kPa}$ dissolved oxygen observed with carbon-limited cultures (Senior et al., 1972). There was an inverse relationship between $Q_{\mathrm{o}_{2}}$ and $Y_{\mathrm{a}}$. After relaxation of the oxygen limitation, the supernatant glucose concentrations rose to a maximum at $22 \mathrm{~h}$ before declining to a lower value as the new steady state was approached 


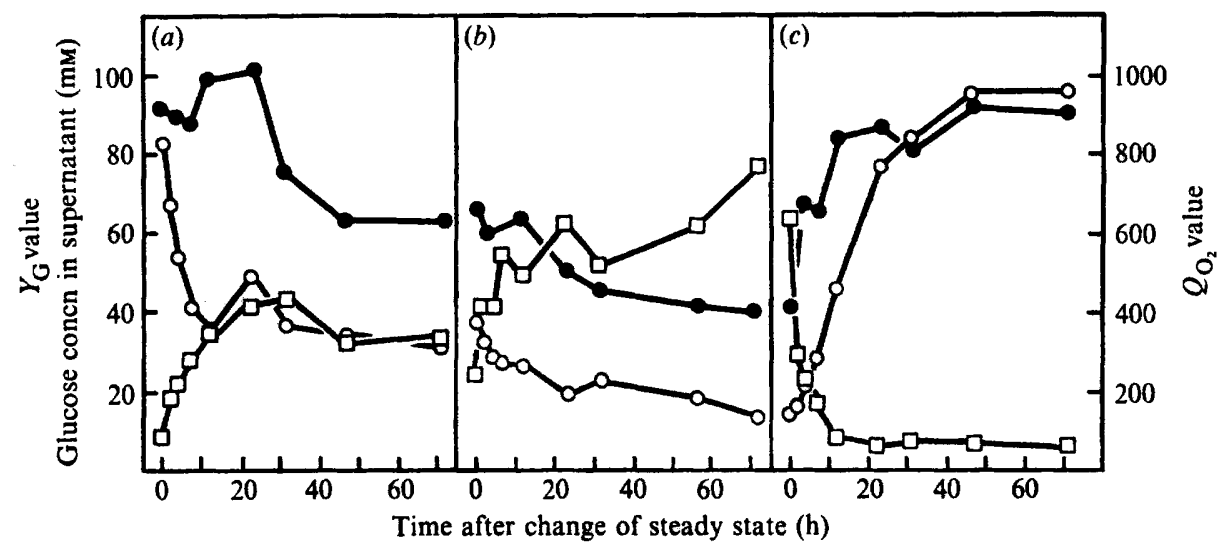

Fig. 4. Effect of transition from oxygen to nitrogen limitation, and vice versa, of a chemostat culture of $A$. beijerinckii on supernatant glucose concentration $(O), Q_{\mathrm{O}_{2}}(\square)$ and observed $Y_{\mathrm{G}}(\bigcirc)$ values. Details as for Fig. I.

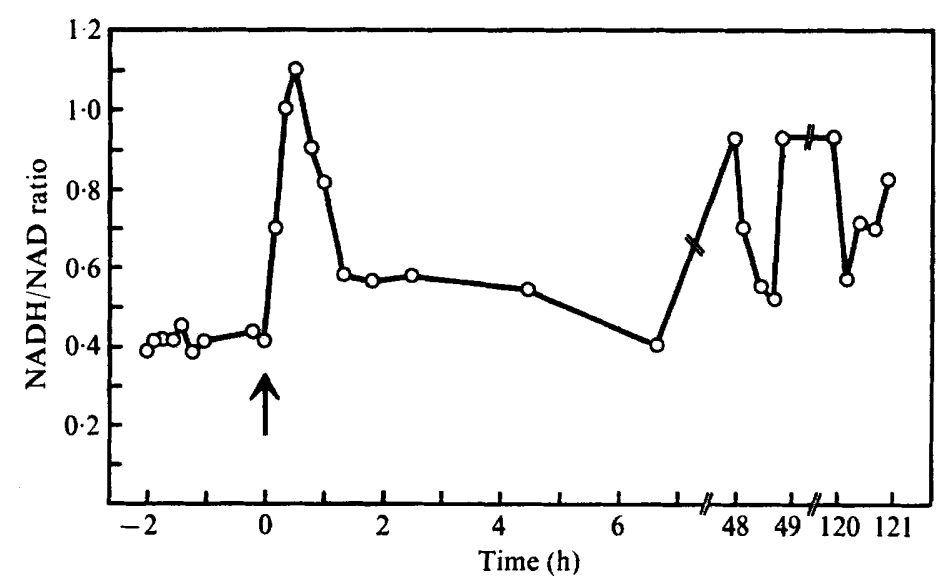

Fig. 5. Effect on the NADH/NAD ratios of $A$. beijerinckii of imposition of an oxygen limitation on a nitrogen-limited culture. Oxygen limitation (undetectable d.o.t.) was imposed at zero time.

(Fig. 4a). Increasing the oxygen concentration (Fig. $4 b$ ) caused a decrease in glucose concentration, indicating that glucose oxidation increased as a respiratory protection function. Conversely, re-imposition of an oxygen limitation led to a rise in supernatant glucose concentration from about $20 \mathrm{~mm}$ to $82 \mathrm{mM}$.

At a similar dilution rate, Senior et al. (1972) observed values of $Y_{\mathrm{G}}$ for oxygen-limited cultures between 48 and 70 . The highest value recorded in the present experiments with $A$. beijerinckii was $9 \mathrm{I}$, which was higher than observed values previously reported for oxygen-limited cultures of Azotobacter vinelandii (Nagai, Nishizawa \& Aiba, 1969; Nagai et al., I97I).

Transition from nitrogen limitation to oxygen limitation: $N A D H$ and NAD levels

Steady-state, nitrogen-limited cultures had $2 \cdot 16 \mathrm{nmol}$ NAD(H) (mg bacterial protein) ${ }^{-1}$ and $0.70 \mathrm{nmol} \mathrm{NADH}(\mathrm{mg} \text { bacterial protein })^{-1}$. These values compare favourably with those of London \& Knight (1966) who found levels of total NAD(H) in strict aerobes of 
$<0.9 \mathrm{nmol}$ (mg dry wt) ${ }^{-1}$ [about $\mathrm{I} .8 \mathrm{nmol}$ (mg protein) ${ }^{-1}$ ]. Wimpenny \& Firth (1972) obtained values of about $5.6 \mathrm{nmol} \mathrm{NAD}(\mathrm{H})(\mathrm{mg} \text { dry wt) })^{-1}$ for strict aerobes, and Kaplan (1960), for Azotobacter agile, detected $0.6 \mu \mathrm{mol}$ NAD(H) (g dry wt) ${ }^{-1}$.

On transition from nitrogen to oxygen limitation (Fig. 5) the NADH concentration increased rapidly for the first $30 \mathrm{~min}$; after about $2 \mathrm{~h}$ NADH was restored to near its previous nitrogen steady-state value. However, the NADH/NAD ratio did not remain constant and there were variations in the oxygen-limited steady-state ratios. Total $N A D(H)$ levels remained constant at $\mathrm{I} \cdot 92 \mathrm{nmol} \mathrm{NAD}(\mathrm{H})(\mathrm{mg} \text { bacterial protein })^{-1}$. Replicate experiments gave similar results and it appears that oscillations in NADH/NAD ratios may occur in the oxygenlimited steady state. These were not investigated further.

\section{Oxo acids in culture supernatants}

The concentrations of pyruvate, 2-oxoglutarate and oxaloacetate in the culture supernatants for oxygen- and nitrogen-limited steady states were always less than $0.05 \mathrm{~mm}$.

\section{DISCUSSION}

A feature of the regulation of PHB metabolism in A. beijerinckii is the partition of acetyl$\mathrm{CoA}$ between the initiating enzymes of the tricarboxylic acid cycle (citrate synthase) and polymer formation ( $\beta$-ketothiolase), effected by the intracellular concentrations of free CoA and NADH (Senior \& Dawes, 1973). This fine control operates in such a manner that, under conditions of oxygen limitation, reducing equivalents which would have utilized oxygen as the terminal electron acceptor are diverted to polymer synthesis, PHB thus serving as an electron sink. Our results show that, following the imposition of an oxygen limitation, the intracellular NADH/NAD ratio immediately increases but then fairly rapidly readjusts as PHB synthesis starts and PHB assumes the role of electron acceptor. Wimpenny \& Firth (1972) found that changing the cultural conditions from aerobic to anaerobic with Klebsiella aerogenes or Escherichia coli caused transient increases in NADH, the level returning to the original after $15 \mathrm{~min}(K$. aerogenes) or $75 \mathrm{~min}(E$. coli $)$; and oscillations in the $\mathrm{NAD}(\mathrm{H})$ redox state have been observed by Harrison, Maclennan \& Pirt (I969) with chemostat cultures of $K$. aerogenes.

In addition to the fine control of PHB metabolism, the levels of certain enzymes of the tricarboxylic acid cycle and of PHB synthesis change in response to variation of the environmental oxygen concentration. Thus two of the essential enzymes of PHB synthesis, $\beta$-ketothiolase and acetoacetyl-CoA reductase, undergo such change, although both are present under highly aerobic conditions when PHB synthesis is minimal.

Nitrogen-fixing Azotobacter present the superimposed feature of respiratory protection of their nitrogenase system (Parker, 1954; Phillips \& Johnson, I96I ; Dalton \& Postgate, 1969; Drozd \& Postgate, 1970), and at higher oxygen concentrations the cytochrome $a_{2}$ content of batch cultures of Azotobacter vinelandii increases, while their energy conservation efficiency decreases (Jones et al., 1973). The NADH oxidase of $A$. beijerinckii is most sensitive to changes in dissolved oxygen concentration and the rapid initial increase in the level of NADH oxidase when the oxygen limitation is relaxed is significant for the oxygen scavenging process of respiratory protection; it is noteworthy that after $12 \mathbf{~} h$ the level of this enzyme falls as the levels of isocitrate dehydrogenase and 2-oxoglutarate dehydrogenase continue to rise. Doubling the dissolved oxygen concentration then causes further increases in the levels of NADH oxidase and 2-oxoglutarate dehydrogenase, but isocitrate dehydrogenase is relatively unaffected. Respiratory activity, as measured by the $Q_{0_{2}}$ value, generally reflects 
the overall pattern of these enzyme levels. However, as isocitrate dehydrogenase initially responds more rapidly than 2-oxoglutarate dehydrogenase, presumably the former enzyme furnishes the increased supply of reducing equivalents for oxygen utilization.

After the relaxation of oxygen limitation there is no significant decrease in the concentration of glucose in the supernatant until $22 \mathrm{~h}$ after the transition, despite the marked increase in $Q_{\mathrm{o}_{2}}$. This observation indicates that the diversion of glucose from PHB synthesis to oxidation does not initially cause an increased rate of glucose utilization. It is unlikely that oxidation of accumulated metabolites such as pyruvate, 2-oxoglutarate or oxaloacetate could contribute much to increased oxidative activity because of their very low concentrations in the culture.

The present findings accord with our earlier suggestion (Senior \& Dawes, 1971) that PHB synthesis serves as an electron and carbon 'sink' at very low dissolved oxygen concentrations.

The regulation of tricarboxylic acid cycle activity by oxygen concentration is well documented for facultative organisms such as $E$. coli (Amarasingham \& Davis, 1965) but we must now ascertain whether the changes observed with $A$. beijerinckii are generally representative of strict aerobes or whether they are a manifestation of respiratory protection and therefore characteristic only of nitrogen-fixing organisms. Additionally the possible effects on tricarboxylic acid cycle activity of intense aeration, of the type recently described by Hine \& Lees (1976) for Azotobacter chroococcum, will be of interest.

We are greatly indebted to the Agricultural Research Council for a grant-in-aid and to Mr Ian D. Marriott for expert technical assistance. We also thank Dr Alan C. Ward for preliminary studies of NAD(P)H/NAD(P) ratio determinations and Dr Peter J. Senior for assistance with some of the preliminary experiments on enzyme levels.

\section{REFERENCES}

AmarasinghaM, C. R. \& Davis, B. D. (1965). Regulation of $\alpha$-ketoglutarate dehydrogenase formation in Escherichia coli. Journal of Biological Chemistry 240, 3664-3668.

BARRERA, C. R. \& JURTSHUK, P. (1970). Characterization of the highly-active isocitrate (NADP ${ }^{+}$) dehydrogenase of Azotobacter vinelandii. Biochimica et biophysica acta 220, 416-429.

Bernovsky, C. \& SwAN, M. (1973). An improved cycling assay for nicotinamide adenine dinucleotide. Analytical Biochemistry 53, 452-458.

BURCH, H. B., BRADLEY, M. E. \& LOWRY, O. H. (1967). The measurement of triphosphopyridine nucleotide and reduced triphosphopyridine nucleotide and the role of haemoglobin in producing erroneous triphosphopyridine nucleotide values. Journal of Biological Chemistry 242, 4546-4554.

BYRNE, G. A. (1965). The separation of 2,4-dinitrophenylhydrazones by thin layer chromatography. Journal of Chromatography 20, 528-540.

Dalton, H. \& Postgate, J. R. (I969). Effect of oxygen on growth of Azotobacter chroococcum in batch and continuous cultures. Journal of General Microbiology 54, 463-473.

Drozd, J. \& PostGate, J. R. (I970). Effects of oxygen on acetylene reduction, cytochrome content and respiratory activity of Azotobacter chroococcum. Journal of General Microbiology 63, 63-73.

Ellman, G. L. (1959). Tissue sulphydryl groups. Archives of Biochemistry and Biophysics 82, 70-77.

Friedemann, T. E. \& Haugen, G. E. (I943). Estimation of $\alpha$-keto acids. Journal of Biological Chemistry $147,415-420$.

Harrison, D. E. F., Maclennan, D. G. \& PirT, S. J. (1969). Responses of bacteria to dissolved oxygen tension. In Fermentation Advances, pp. 1 I7-144. Edited by D. Perlman. London and New York: Academic Press.

HINE, P. W. \& LEES, H. (1976). The growth of nitrogen-fixing Azotobacter chroococcum in continuous culture under intense aeration. Canadian Journal of Microbiology 22, 6I I-618.

JENSEN, H. L. (1954). The Azotobacteriaceae. Bacteriological Reviews 18, 195-214.

Jones, C. W., Brice, J. M., Wright, V. \& ACKRELl, B. A. C. (1973). Respiratory protection of nitrogenase in Azotobacter vinelandii. FEBS Letters 29, 77-81.

KaPlan, N. O. (1960). The pyridine coenzymes. In The Enzymes, vol. 3, 2nd edn, pp. 105-187. Edited by P. D. Boyer, H. Lardy and K. Myrbäck. New York: Academic Press. 
LAW, J. H. \& SLEPECKY, R. A. (196I). Assay of poly- $\beta$-hydroxybutyrate. Journal of Bacteriology 82, 33-36.

LONDON, J. \& KNIGHT, M. (1966). Concentrations of nicotinamide nucleotide coenzymes in micro-organisms. Journal of General Microbiology 44, 24I-254.

Nagal, S., NishizaWA, Y. \& Aiba, S. (I969). Energetics of growth of Azotobacter vinelandii in a glucoselimited chemostat culture. Journal of General Microbiology 59, 163-169.

Nagai, S., Nishizawa, Y., ONodera, M. \& Aiba, S. (197I). Effect of dissolved oxygen on growth yield and aldolase activity in chemostat culture of Azotobacter vinelandii. Journal of General Microbiology 66, 197-203.

OediNG, V. \& SCHLEGeL, H. G. (1973). $\beta$-Ketothiolase from Hydrogenomonas eutropha HI 6 and its significance in the regulation of poly- $\beta$-hydroxybutyrate metabolism. Biochemical Journal 134, 239-248.

PARKer, C. A. (1954). Effect of oxygen on nitrogen fixation by Azotobacter. Nature, London 173, 780-781.

Phillips, D. A. \& Johnson, M. J. (1961). Aeration in fermentations. Journal of Biochemical, Microbiological and Technical Engineering 3, 277-309.

SENIOR, P. J. \& DAWES, E. A. (197I). Poly- $\beta$-hydroxybutyrate biosynthesis and the regulation of glucose metabolism in Azotobacter beijerinckii. Biochemical Journal 125, 55-66.

SENIOR, P. J. \& DAWEs, E. A. (1973). The regulation of poly- $\beta$-hydroxybutyrate metabolism in Azotobacter beijerinckii. Biochemical Journal 1 34, 225-238.

Senior, P. J., BeEch, G. A., Ritchie, G. A. F. \& Dawes, E. A. (1972). The role of oxygen limitation in the formation of poly- $\beta$-hydroxybutyrate during batch and continuous culture of Azotobacter beijerinckii. Biochemical Journal 128, $1193-1201$.

SHERMA, J. \& ZWEIG, G. (I97I). Keto acids. In Paper Chromatography and Electrophoresis, vol. II, pp. 173174. Edited by G. Zweig and J. R. Whittaker. London and New York: Academic Press.

StockDale, H., RiBbons, D. W. \& Dawes, E. A. (1968). Occurrence of poly- $\beta$-hydroxybutyrate in the Azotobacteriaceae. Journal of Bacteriology 95, $1798-1803$.

WiMPENNY, J. W. T. \& FiRTH, A. (1972). Levels of nicotinamide adenine dinucleotide and reduced nicotinamide adenine dinucleotide in facultative bacteria and the effect of oxygen. Journal of Bacteriology IIr, 24-32. 